\title{
Workshop Cidade Ciclável
}

\author{
Cyclable City Workshop
}

\author{
SANTOS, Ana Paula Silveira dos; Mestra em Design Estratégico; UNISINOS \\ anapsilveira@edu.unisinos.br
}

BENTZ, Ione; Prof. a Dra. PPG Design; UNISINOS

ioneb@unisinos.br

\section{Resumo}

Na dimensão do design estratégico, o exercício de metaprojetar a construção de uma Cidade Ciclável pode contribuir para o desenvolvimento das cidades que apresentam um contexto frágil, se interpretada pela lógica da inovação social que gera valor. Neste sentido, compreende-se contexto frágil como um espaço onde há uma malha cicloviária que foi adaptada às faixas de circulação de carros e pedestres, sendo inserida de forma forçada e impositiva no espaço urbano. Assim, estabeleceu-se como objetivo geral elaborar projetos de cenários para um contexto frágil de mobilidade ciclável. Este artigo foca em um dos ciclos dos movimentos metodológicos realizados no percurso da pesquisa Desafios para uma Cidade Ciclável: Um Exercício de Design Estratégico. A aplicação na prática do workshop Cidade Ciclável reuniu um grupo de participantes que projetaram cenários futuros para a construção da Cidade Ciclável.

Palavras Chave: cidade ciclável; processos metaprojetuais; projeto por cenários.

\begin{abstract}
In Strategic Design, the exercise of metadesign in order to project a Cyclable City can contribute towards the development of those cities whose transportation infrastructure is less than ideal, if this exercise is viewed through the lens of value-generating social innovation. In this context, a less than ideal infrastructure' means an urban space in which there is a cycling network which has been adapted to the existing traffic infrastructure, in a manner that is unnatural or imposed. Therefore, the aim of this paper is to project imaginary scenarios for a city whose transportation infrastructure is of the aforementioned type. This article focuses on one of the cycles of methodological movements conducted in the search Challenges for a Cyclable City: A Strategic Design Exercise. The practical implementation of the workshop brought together participants who designed future scenarios for the Cyclable City.
\end{abstract}

Keywords: cyclable city; metadesign process; Project by scenarios. 


\section{Construção da Cidade Ciclável}

É inspirada nos conceitos de cidade polifônica e do perder-se na cidade que se define o ponto de partida da pesquisa Desafios para uma Cidade Ciclável: Um Exercício de Design Estratégico. Estabeleceu-se como objetivo geral elaborar projetos através de cenários para um contexto frágil de mobilidade ciclável. Este artigo tem como foco apresentar um dos ciclos dos movimentos metodológicos desenvolvidos nesse estudo e caracterizado como Workshop Cidade Ciclável. Tal movimento metodológico, associado aos demais na pesquisa, busca a construção de um conceito acerca da Cidade Ciclável à luz do design estratégico.

O uso da bicicleta como transporte alternativo para deslocamentos de pequenos e médios trajetos ganha espaço dentro da temática mobilidade urbana, circunstância elaborada para que as pessoas possam se deslocar de um ponto ao outro pelas diversas regiões de uma cidade. A mobilidade caracteriza-se como um dos principais desafios das metrópoles mundiais contemporâneas porque reúne questões de ordem ambiental e urbana e estão relacionadas ao desenvolvimento socioeconômico-cultural. Diante dessa situação, as cidades passam a incentivar a bicicleta, visto que essa possibilita deslocamentos ágeis e, quando combinada com o transporte coletivo, facilita o percurso em trajetos subsequentes. No Brasil, as cidades dispõem de uma estrutura discreta e, por vezes, problemática para incorporar a bicicleta como transporte alternativo capaz de auxiliar na mobilidade urbana. Neste estudo, compreende-se contexto frágil como um território que não prioriza o transporte alternativo por meio da bicicleta como prática efetiva nos deslocamentos diários das pessoas e que dispõe de dispositivos físicos, atores objetos, como: ciclovias, ciclofaixas e ciclorrotas inseridos de maneira que tanto incomoda pedestres, ciclistas e motoristas. Uma malha que interrompe o traçado original que tem como prioridades a circulação de automóveis e coletivos, que não foi criada para a circulação de bicicletas, sendo inserida de forma forçada e impositiva no espaço urbano. Um contexto frágil entende-se ainda como um ambiente que vive na imperfeição e não compreende que o sujeito-corpo se encontra exposto na cidade. A proposta, então, é reconhecer o contexto frágil e projetar dentro da ideia de imperfeição.

Na dimensão do design estratégico, o exercício de metaprojetar uma Cidade Ciclável pode contribuir, substancialmente, para o desenvolvimento das cidades que apresentam um contexto frágil, se interpretada pela lógica da inovação social, gerando valor. Isso porque a questão não apenas se encerra na aplicação prática de dispositivos nas cidades, entretanto, implica em atuar de maneira projetual em ecossistemas criativos que estimulam inúmeras relações. Franzato (2015) compreende ecossistema criativo como um ambiente configurado pelo desenvolvimento de processos criativos, que resultam em dispositivos sociotécnicos, que ora podem ser inovadores, ora originais. É quanto há de oportunidade para a tomada de consciência que tem a intenção de evoluir na direção de um estilo de vida sustentável, oportunizando a fluidez nos deslocamentos das pessoas por meio da bicicleta e reconhecendo os atores da rede de relações que se estabelece sustentada por influências, usos e desejos.

A cidade polifônica, Canevacci (1997), é uma cidade narrada por meio de diversas técnicas interpretativas e que procuram dar voz às muitas vozes, sendo a polifonia encontrada no objeto e no método. A etnografia urbana auxilia no entendimento da cidade como um todo e pela especificidade das partes, bem como na comunicação urbana, assumindo a ideia de coro, onde as mais variadas vozes estão presentes desenvolvendo-se de forma independente, porém, dentro de uma mesma tonalidade. Acrescenta-se também o conceito 'do se perder na cidade', que favorece o desenraizamento e isolamento para só, então, reconstruir uma nova personalidade para a cidade. 
No que se refere à mobilidade por bicicleta, é preciso considerar que o ciclista já não é mais apenas o de fim de semana, aquele modo de lazer ou brincadeira; ele se desloca para o trabalho por meio de dispositivos - ciclofaixas, ciclovias e ciclorrotas - que começam a mostrar sinais de presença e de influências nas cidades brasileiras. Se considerarmos uma Cidade Ciclável como um ecossistema criativo e aberto, há ambiente para observar e pesquisar o que, realmente, é capaz de transformar uma cidade em ciclável.

A cidade de Porto Alegre, no Estado do Rio Grande do Sul, Brasil, foi o laboratório escolhido para a aplicação da pesquisa por se caracterizar um contexto frágil, em função de um plano ciclável traçado pela cidade na década de 1980 e que está distante de uma operação plena. O plano não saiu do papel por inúmeros motivos, entre eles o de políticas públicas. De acordo com levantamento da área de Projetos e Estudos de Mobilidade da EPTC, os porto-alegrenses têm 41 quilômetros de ciclovias disponíveis para seus deslocamentos, lazer ou trabalho, que não atingem nem mesmo a marca de $10 \%$ da quilometragem proposta que é de 495 quilômetros no total. (PORTO ALEGRE, 2016b).

A relevância social e econômica deste estudo procede da necessidade de facilitar os deslocamentos, desenvolver consciência sustentável, espírito de inovação social, a melhoria das condições gerais da saúde dos indivíduos, gerar menor custo na locomoção urbana e menor produção de poluição por meio de gás carbônico. A relevância científica refere-se ao uso de metodologias específicas do design estratégico que contribuem para que se abra um caminho para o desenvolvimento do conceito de Cidade Ciclável, pelos pilares do design e do exercício da prática metaprojetual. Busca-se na processualidade da projetação por cenários futuros alternativas para construção de uma cidade mais amigável. A relevância metodológica está na abordagem do design estratégico, onde o método foi caracterizado por dois momentos distintos: o primeiro de observação do espaço das rotas cicloviárias - ciclovias, ciclofaxias e ciclorrotas - nas vias selecionadas como relevantes; seguida das entrevistas com os usuários, conforme critérios estabelecidos, e que neste artigo não será explorado. O segundo, um laboratório experimental, denominado na pesquisa de Workshop Cidade Ciclável, criado com o objetivo de projetar cenários futuros para uma cidade que se movimenta por bicicleta. Concebe-se este artigo inserido na intersecção entre os domínios dos estudos de design e sociedade, que abarcam a inovação social, do codesign e da sustentabilidade no espaço urbano. Assimilar os mecanismos, as práticas e as estratégias do design que impactam na organização de uma Cidade Ciclável, onde as adversidades estão presentes de modo permanente e nas relações estimuladas entre os atores sujeitos e atores objetos, possibilitando estabelecer uma processualidade ciclável.

\section{Cidades são pessoas}

As origens do conceito de urbanidade remetem à noção de cidade e urbano. A cidade caracteriza-se como um espaço físico que reúne uma gama de elementos relacionados à infraestrutura e à população. E o urbano, a tudo o que se refere à vida na cidade. É pela urbanidade que se desenvolve a noção de civilidade, na qual os cidadãos assumem a condição de conviver em espaços públicos abertos e fechados. Na década de 1960, surge a vitalidade urbana proposta por Jacobs (2011), que discorre sobre os problemas gerados nas cidades americanas que estavam relacionados à falta de demarcação entre espaços públicos e privados, aos parques urbanos segregados, às calçadas problemáticas etc. Logo, uma crítica aos espaços que não eram convidativos à circulação das pessoas numa cidade. Uma vez que se tenha a compreensão de que cidades englobam interações interpessoais que ora são favorecidas pela infraestrutura, ora são dificultadas, 
é possível entender que a urbanidade está imbricada na vitalidade urbana, pois não existe urbanidade sem vitalidade. É pela experiência com o outro, a integração e o reconhecimento da diversidade que se tensionam as relações e não relações na cidade. A urbanidade também é fruto das idiossincrasias de cada cidade, bem como da projeção de formas de vida mais ou menos integradas e que ainda incluem segregação e violência. (NETTO, 2013).

Pelo paradigma da complexidade, que contribui de forma considerável para a pesquisa em design, a teoria de Morin (2011) tem como princípio colocar em dialógica, a ordem, a desordem e a organização. Os sistemas vivem em ordem e desordem, nos quais o todo se diferencia da soma das partes e estabelece a reflexão paradoxal do uno e do múltiplo. É o pensar o todo norteado pela crítica sobre o próprio pensar e os métodos, retornando ao começo e, tal dinâmica movimentada pela ordem e pela desordem ruma à ideia de auto-organização que transforma o indivíduo e, além dele, o meio em que ele vive. Para que o raciocínio acerca de territórios e cidades criativas seja assimilado, se torna relevante estabelecer os conceitos. Territórios caracterizam-se como a extensão ampla do espaço de uma cidade sobre o qual se tem identidade e a ideia de pertencimento. Assume-se a definição de Reyes (2015), na qual o território - pedaço de terra engloba uma cidade com todas as suas potencialidades e processos, além das aspirações e atritos. O território é sensível ao sentido de desenvolvimento e a presença das relações que se estabelecem na interligação entre o social e as formas concretas presentes nesse espaço. Assim, se poderia agregar ao pensamento de Reyes a noção de território social com uma cultura aberta ao risco e à cooperação estratégica de agentes socioeconômicos-culturais que, conforme sua processualidade, revela a cidade criativa, sendo a comunicação de novas ideias a facilitadora do desenvolvimento e da transformação de novos produtos, serviços e materialidades.

Se pensados pela dialógica de apropriação de territórios, identidade e pertencimento os deslocamentos por bicicleta conectam ruas, bairros e pessoas de diferentes regiões das cidades, carregando a ideia intrínseca sustentável, menos sedentária, com a apropriação dos espaços urbanos e com fluidez nos deslocamentos. As bicicletas convidam à mobilidade, ou seja, andar pela cidade por outro tipo de veículo e de forma mais sensorial. A cada novo deslocamento imbricado desses ideais sociais, a pele da cidade se altera, sofrendo interferência direta, em tempo real. (CANEVACCI, 1997; BENTZ, 2014). A cidade passa a ser revelada como uma obra coletiva resultante do desenvolvimento e dos movimentos processuais dados no meio social, cujos modelos produzidos pela ciência e pela arte geram inúmeros valores, seja de uso ou desfrute. (BENTZ, 2015). Por meio de uma linguagem semiótica, o ser humano interpreta os elementos e o ambiente que lhe envolve ao atribuir significado a tudo o que gira em torno dele. Quando se compreende o mundo pela lógica do pensamento rumo à complexidade, o sistema já é uma operação onde o sujeito e o objeto não se distinguem, pois operam na intersubjetividade. (CHARAUDEAU, 2009; FURTADO, 2002; ORLANDI, 2001). Na visão de Orlandi (2001), o sujeito urbano se revela como corpo que se materializa como capital que se encontra empreendido. A partir de um espaço de memória particular, a subjetividade preenche tal espaço e libera a noção de eu urbano. A metáfora do corpo designa que nos gestos estão o sentimento da linguagem, o recorte da formulação e o meio que ela percorre. Consequentemente, todo o equipamento urbano revela cicatrizes na cidade provocadas por este sujeito urbano, sujeito-corpo. São marcas e registro de memórias que, à luz do design estratégico, são insumos para o reconhecimento do que há em um determinado espaço/tempo.

As pessoas são as cidades e as cidades são as pessoas. Os seus fluxos desenham a construção de sentido nos espaços urbanos. É pelo ir e vir que surgem descobertas ao longo de todo o mover- 
se das pessoas pelo território. O território dá forma a uma cidade, quando esse estabelece uma relação fluida entre o contexto natural e as estruturas físicas, existindo a compreensão de que estes espaços ainda são preenchidos por vida humana. (FURTADO, 2002). Se há o desejo de uma mobilidade urbana ciclável, consequentemente sustentável e eficiente nas cidades, tal processo passa pela abordagem design estratégico. A sustentabilidade deveria ser o meta-objetivo das pesquisas na área, uma vez que esse tem a habilidade de colocar em prática descontinuidades sistêmicas e contribuir para mudanças efetivas. Mazini (2008) entende que para atingir tal mudança é necessário que se institua um processo de aprendizagem social. A transição rumo à sustentabilidade tornar-se-á um processo de aprendizagem social quando os seres humanos aprenderem com ele a prática do viver bem, consumindo bem menos recursos ambientais e regenerando a qualidade dos contextos onde vivem. Se por um lado é simples; por outro, é complexo e requer mudanças sistêmicas.

Projetar para cidades criativas significa projetar uma dimensão cultural que ative ambientes. Também é expressivo que se atue em nível metaprojetual para sustentar a inovação social, influenciando de forma crítica na proposição de artefatos ou processos que abram caminhos criativos para a cocriação de novos significados sociais. (GIACCARDI, 2005). É a partir da forma como o designer vê e experiencia o mundo, que desenvolve a capacidade de realizar uma leitura qualitativa e interpretativa das realidades na prática. Para Bentz e Franzato (2016), o designer empenha-se em elencar os elementos que serão o alicerce das possíveis soluções para além dos valores econômico, social, cultural e estético. Os processos de criação de dispositivos (artefatos, processos, sistemas) buscam alterar a realidade existente. Tais processos englobam criatividade, imanência, prospectividade e transitividade, levando à reflexão sobre o caráter transitório do metaprojeto cujos movimentos de planos e corpos atuantes se caracterizam pela provisoriedade e mutabilidade. O sentido de metaprojeto pode ser entendido como um ato de reflexão crítica e reflexiva sobre o respectivo projeto, afirma De Moraes (2011), oriundo da ideia de uma plataforma de conhecimento com inúmeros atores envolvidos e sendo capaz de sustentar e orientar a atividade projetual num cenário de mutação constante e ao mesmo tempo fluído. Portanto, aplicar metaprojeto é empenhar numa conquista por visões e cenários possíveis que sejam decompostos e decodificados diante dos ciclos de vida. Vale-se tanto dos pontos positivos quanto dos negativos para que a cultura do design seja entendida como uma área do conhecimento estratégico e avançado, instituída dentro da complexa forma de se relacionar de uma sociedade.

A construção de projetos por cenários estimula um processo de projeto mais aberto, no qual a ideia metodológica visa à orientação e revisão a todo o tempo. Isso porque quando se projetam cenários com base nas diferenças e no contraditório, não se deseja corrigir as imperfeições, segundo Reyes (2015), mas aproveitar os insumos produzidos e expostos pelos atores sociais que possam ter sido esquecidos ou deixados de lado ao longo do processo. A imagem, dentro de um processo de projeto, passa a ter autonomia quando essa transpõe a ideia como reflexo do real, ou seja, ela se liberta da função e propósito original e funciona como processo criativo. Assim, por meio da realidade, ao longo do processo, a imagem vai constituindo uma nova possibilidade projetada que repercute fora do ser e tende a ir na direção de outras subjetividades. É por meio delas também que os atores sociais conseguem vislumbrar e criar novas imagens para um desejo futuro de cenário. A imaginação é o meio pelo qual o projeto opera e revela o ato de projetar. As imagens dão sentido a toda essa operação. E é o resultado de todo este tensionamento de imagens combinadas com o ato da ação metaprojetual que, em meio a essa interação entre a cidade e as pessoas, nascem os valores das cidades. Para Meroni (2008), cenários são visões compartilhadas que decodificam informações e 
intuições em conhecimento perceptível. Neles, se pode projetar, por exemplo, uma Cidade Ciclável que auxilie na fluidez dos deslocamentos entre as pessoas que tanto seja para deslocamentos diários que envolvem rotinas de trabalho quanto para lazer. Um sistema que conceba fluidez na vida das cidades e de quem nelas habita. A construção dos cenários pela ótica do design, segundo Manzini e Jégou (2006), engloba histórias que embasam os projetos dos futuros sistemas. Os cenários aplicados nos processos de projeto enfatizam o espaço destinado a facilitar o processo projetual e estimulam a habilidade de combinar uma série de disposições de maneira perspicaz no desenvolvimento de estratégias.

A metodologia de projetos por cenários abordada por Reyes (2015) traz para o centro da discussão a síntese e a não síntese, ou seja, que se orienta pelo dissenso e promove o rompimento interno, possibilitando que ao longo do processo se abram novas alternativas para o projeto. 0 modelo teórico proposto pelo autor parte de um sistema aberto com linhas abertas com agentes de significação que a todo o instante vão validando sínteses parciais dentro do sistema, e ao mesmo tempo confrontando-as para que as interferências em momentos distintos possam oxigenar o sistema a qualquer momento no decorrer do processo. A ação de metaprojetar está fundada no percurso sistêmico do processo do projeto, uma vez que projetar é ensaiar sentidos, esses já são dados por parte de análises e interpretações entre atores e contextos e seus vínculos. (REYES, 2015). Esses vínculos assumem diferentes posições ao longo do processo de projeto e são insumos relevantes para o processo de criação. Ao lado do metaprojeto entra em cena a semiótica que também pode auxiliar no processo projeto pela sua capacidade de, em parceria com a comunicação, estimular movimento dos sentidos que se formam através das intenções, que devem ser expostas para serem reconhecidas pelas pessoas. De todo o processo de projeto por cenário nasce uma narrativa, um tipo de texto que revela uma sucessão de acontecimentos que são tramados ao longo do processo de projeto. Elos que são interligados num sistema de forma flutuante e não rígida e que produzem sentido e significação. (BENTZ, 2015; CANEVACCI, 1997; ORLANDI, 2001).

O presente artigo apropria-se da espontaneidade metodológica polifônica de Canevacci (2005), que dá voz às inúmeras vozes. Optou-se por um percurso que teve início com um exercício dedutivo e que com base nos achados no campo. Esses achados foram submetidos à perspectiva do modelo de método de análise de conteúdo pela visão de Fontanille (2005), que elabora uma hierarquia e um percurso de níveis de pertinência semiótica como forma de organizar as informações. Os achados serviram de insumo para o desenvolvimento do passo seguinte: a retomada do design estratégico como prática projetual abdutiva lançando-se mão da ideia da construção do conceito sobre Cidade Ciclável. À luz do design estratégico e enfrentando a ideia de contexto frágil, foi realizado um workshop denominado Cidade Ciclável. Esse movimento metodológico enfocou a projetação de cenários possíveis estimulado pelo norteador de como se vivencia e pratica a circulação de pessoas numa cidade por meio da bicicleta e o que se pode pensar para além do já existente a respeito de uma possível Cidade Ciclável.

\section{Pedalando pelo Workshop}

Neste workshop (WS), formado por um grupo de participantes que se caracterizaram por ciclistas e não ciciclistas, instigou-se a reflexão acerca de uma Cidade Ciclável orientada pelo design estratégico. O início da atividade de Workshop Cidade Ciclável 2018 aconteceu com base na apresentação do desenvolvimento da pesquisa de mestrado em design intitulada: Desafios para uma Cidade Ciclável: Um Exercício de Design Estratégico. A pesquisadora fez uma rápida contextualização sobre o tema mobilidade urbana ciclável, sobre a ideia da pesquisa acerca da 
construção de um conceito de Cidade Ciclável, bem como as noções de design estratégico, partindo para uma breve explicação a respeito da proposta do WS, no qual a finalidade era a projetação de cenários futuros. $\mathrm{Na}$ apresentação realizada foram utilizados como recurso uma apresentação em PowerPoint contendo informações sobre design estratégico, metaprojeto, ecossistema, mapa de atores, tudo acerca da ideia de se construir um conceito de Cidade Ciclável guiado pelo design estratégico e sustentado pela metodologia de processo de projeto por cenários. Nessa orientação inicial foi posto o problema: projetar cenários para uma Cidade Ciclável com base em contexto frágil, utilizando-se da metodologia de projetar por cenários.

O WS foi estruturado para acontecer em duas horas, reuniu 6 participantes escolhidos a partir do critério de quem pedala com frequência e de quem vive a cidade a pé. O grupo do WS foi formado por 3 ciclistas, 3 pedestres e 2 designers que interferiram em determinados momentos para apontar caminhos levantados pelos próprios participantes e tensionar em outros. A técnica aplicada para o desenvolvimento de cenários futuros contou com uma seleção de imagens, captadas da internet, que envolviam a temática bicicletas e cidades, recursos de materiais como: folhas, canetas, tesouras e pequenos bonecos de brinquedo, etc., e um momento inicial de discussão.

Os primeiros 30 minutos do WS foram dedicados à discussão, na qual apareceram questões relacionadas aos valores do grupo participante. Eles trouxeram experiências e exemplos do dia a dia, situações vividas por eles e algumas ideias de enfrentamento do problema. Foram feitas interferências de tensionamento por parte de um dos designers presentes. O processo de projeto do grupo aconteceu conforme descrição a seguir. Para efeito de preservação da identidade dos participantes, cada um deles teve o nome alterado para as seguintes denominações: PWS1, PWS2, PWS3, PWS4, PWS5 e PWS6, e assim serão identificados nesta pesquisa, bem como a contribuição dos 2 designers, respectivamente, D1 e D2.

\subsection{Explosão de Ideias}

A discussão inicial teve como foco valores percebidos e levantados pelo grupo - formado por participantes desconhecidos entre si. Informações como: um deles já ter feito parte de grupo de cicloativistas, colocou no centro da conversa que há um problema sério entre os cicloativistas. Ou seja, que se traduz pela necessidade de convencer diferentes pessoas a utilizarem a bicicleta e esse ser o caminho viável ou até mesmo o melhor caminho. Tal pensamento, segundo Participante Workshop 1 (PWS1), fomenta a ideia disseminada no meio dos ciclistas de que eles não devem ser punidos pelas regras de trânsito porque desestimularia a prática da bicicleta nas cidades: " $A$, $t u$ propões uma solução e está te cegando aos problemas que vêm junto com ela". (PWS1). A partir desta primeira colocação, os demais participantes foram verbalizando frases como: "Na verdade, Porto Alegre é uma cidade de imobilidade urbana, falta espaço para todo mundo". (PWS2). "Falta é educação para todo mundo". (PWS3).

Em meio à discussão inicial e aos apontamentos foram lançadas ideias, tais como as de que as pessoas são, em diferentes momentos, condutoras de qualquer espécie e que se faz pertinente a compreensão de que também há outros condutores que precisam das mesmas coisas. Então, surge no grupo a noção de que não se está sozinho neste mundo e que deve haver um pouco de parcimônia, segundo eles. Outra ideia que aparece de forma explícita durante o WS, destinado à discussão e familiarização acerca do tema, é a da grande cidade linda e possível através da seguinte expressão: "[...] um grande parque sem ciclovia, sem ciclofaixa, sem nada, todos andando de bike ou andando a pé, mas com educação, respeitando tamanhos e tipos de pessoas e veículos". (PWS3). 
Após a sequência de ideias e relatos, o designer (D1) interferiu no grupo resgatando o conceito de cenário, orientando o grupo para noções de visualização e imaginação para que fossem mais bem absorvidas e gerassem uma relação com as primeiras ideias expressadas nas falas dos participantes. A motivação também se fez pertinente para tirar o grupo da zona de conforto. 0 PWS4 questionou o grupo perguntando: "[...] qual será o primeiro passo a pensar nesta cidade ciclável do futuro? Em se pensando em idades distintas, como andar de bicicleta numa cidade com lombas e pessoas acima de 60 anos ou pessoas que não têm capacidade de pedalar?". Junto ao questionamento, PWS5 expôs a compreensão de futuro: "O futuro para mim é muito mais vários meios do que só pedestres e ciclistas". PWS4 levanta a possibilidade de que talvez seja mais fácil fazer todos esses meios se integrarem. "Acho que não dá para pensar em melhor numa cidade. Acho que tem que pensar o que é mais viável conforme a circunstância. O melhor talvez fosse ele pegar um transporte coletivo, pensando neste exercício futurista, que tivesse um espaço para colocar a bike e onde tivesse microrodoviárias ou bicicloviários ou qualquer coisa assim que os caras pudessem parar em determinados pontos da cidade e dali ir de bike para onde ele quer ir, é um futuro. Futuristamente, pensando, é isso. É pensar numa ideia circular, um centro. A gente não tem um centro, centro. Mas, ter zonas nas cidades onde tu possas parar e pegar este transporte coletivo dali em diante. A própria questão da bike alugada é uma coisa a ser pensada. Ok, talvez daqui a 100 anos, 50 anos, 30 anos não vai ter bike, mas vai ter uma quantidade de bicicletas de uso comum ou até os carros de uso comum". PWS2 acredita que a ideia para as cidades não seriam ciclovias e sim uma terceira faixa de rodagem, como é com os carros e onde os veículos mais lentos vão pela direita. "É a ideia de PWS3 de pequenos oásis, que seriam locais onde tu vais ter bomba, vais ter pneu, vais ter lugar para descansar, máquinas com câmeras, tu não compras cerveja em máquinas? Compra câmeras de pneu também. Este tipo de foco seria bastante factível para as cidades".

Durante as inúmeras interferências e pensamentos durante o processo de explosão de ideias e percepções, a equipe do workshop ia e voltava para questões relacionadas ao dia a dia vivido por elas e pelas vivências de pessoas próximas a esse universo. A questão que aparece marcante é a necessidade de que num futuro haja uma conscientização, uma mudança de pensamento e no modo de agir das pessoas, numa noção de coletivo. "Antes acho que tem que fazer um planejamento de educação para isso para todos se educarem. De repente ensinar a andar de 'bike' na educação física do colégio, questões básicas de civilidade [...] pensar em algo padrão para evitar problemas?", argumenta PWS4.

A pesquisadora realizou mais uma interferência provocativa trazendo para o grupo a ideia de que se o assunto é mobilidade e por que eles estavam todos no mesmo lugar? Ou seja, parados? O corte foi fomentado pela compreensão por parte da pesquisadora e dos designers de reforçar a noção de projetar cenários através da explosão de ideias e também por meio de uma materialidade, capaz de dar uma corporeidade ao processo de projeto de cenários que estava em desenvolvimento durante o WS. Enquanto alguns participantes do grupo continuaram a discussão e a trazer exemplos; outros, realizaram uma movimentação pelo espaço da sala e se transferiram para uma mesa maior com o objetivo de começar a projetar os cenários falados e discutidos na primeira parte do WS. Esse foi o início dado ao processo de visualidade; e apenas um, que era de origem irlandesa, começou o relato da experiência dele na cidade de Dublin, Irlanda. O ponto que chamou a atenção e fez o grupo concentrar no relato de PWS6, foi a questão de que em Dublin, há 30 anos, a cidade não era amigável para bicicletas. Agora todo mundo lá tem bicicleta e as pessoas a utilizam para se deslocarem para o trabalho. PWS6 chama atenção que o primeiro passo não foi uma mudança de infraestrutura da cidade, isso veio depois. Mudaram, sim, a consciência de motoristas e a atitude dos ciclistas diante da condição de vitimização. PWS6 ainda trouxe a informação de que também, 
hoje, a cidade não tem uma linha, uma ciclovia exclusiva, tanto as pessoas quanto os carros sabem e reconhecem os seus lugares para circular. A sugestão dada por PWS6 no final foi a de que as pessoas têm que defender a ideia de: pedestres número 1; ciclistas número 2, e carros número 3 , ônibus e outros. Além disso, para mudar a consciência das pessoas, elas também precisam lutar. As imagens do processo de projeto por cenários ilustram esse percurso com base nas Fotografias 1, 2, 3 e 4, que se mostram na sequência. Nas Fotografias 1 e 2, aparecem o grupo de participantes na fase de discussão.

Fotografia 1 - Discussão inicial: posição das pessoas

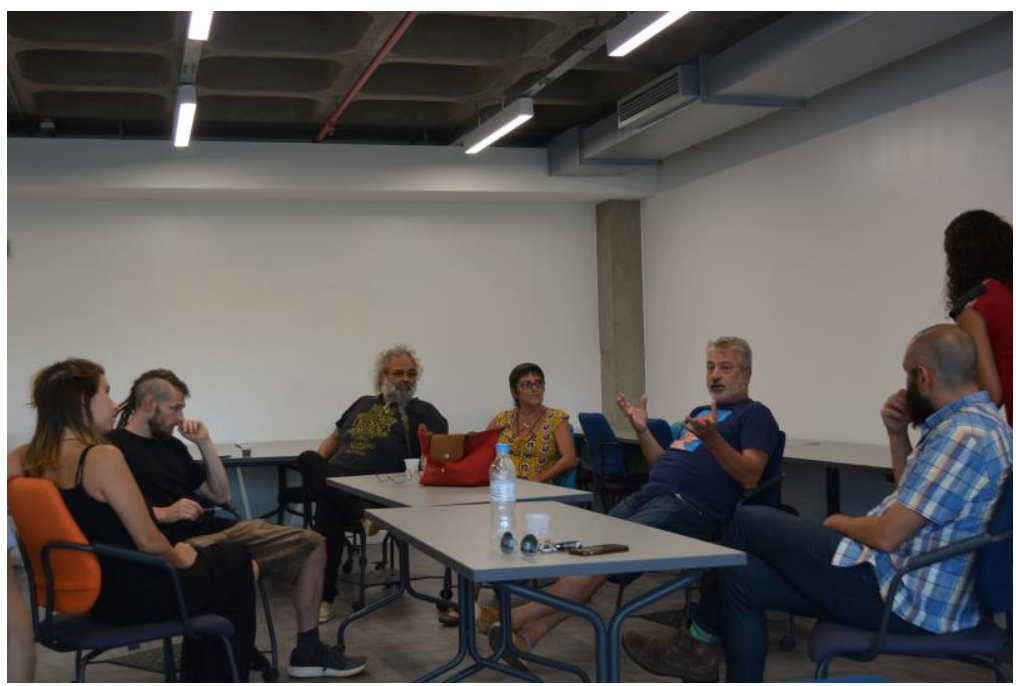

Fonte: Registrada por Rodrigo Najjar.

Fotografia 2 - Discussão inicial: movimento das pessoas

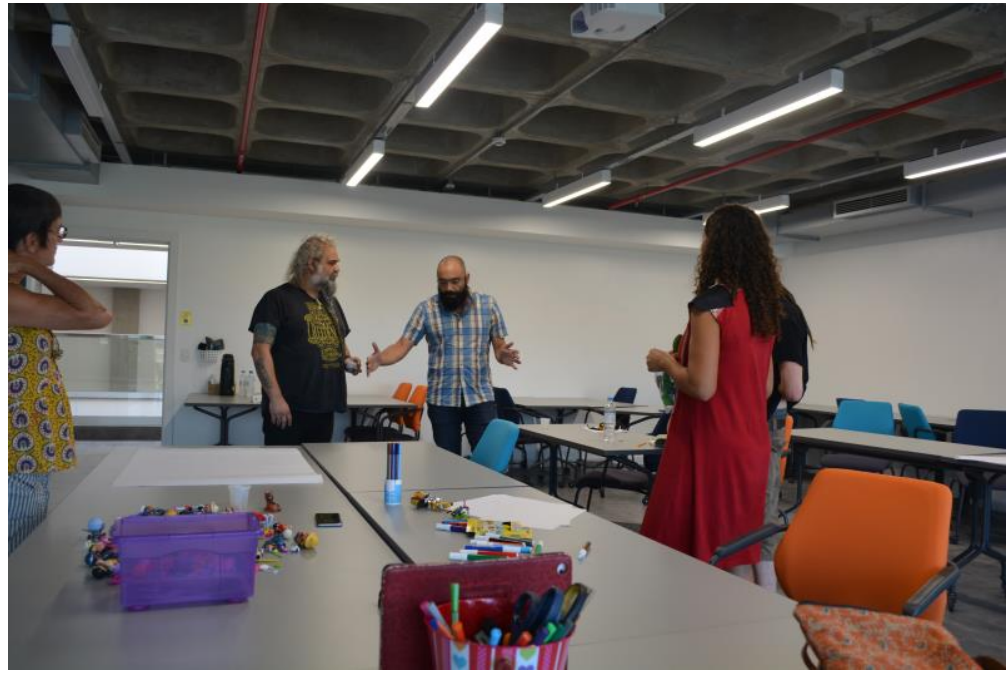

Fonte: Registrada por Rodrigo Najjar.

A materialidade projetada pelo grupo ganha forma à medida que uns vão se movendo e discutindo sobre o assunto. Os primeiros movimentos ainda são tímidos e imprecisos. Revelam bem um processo de construção - Fotografia 3. 
Fotografia 3 - A materialidade em processo de projetação

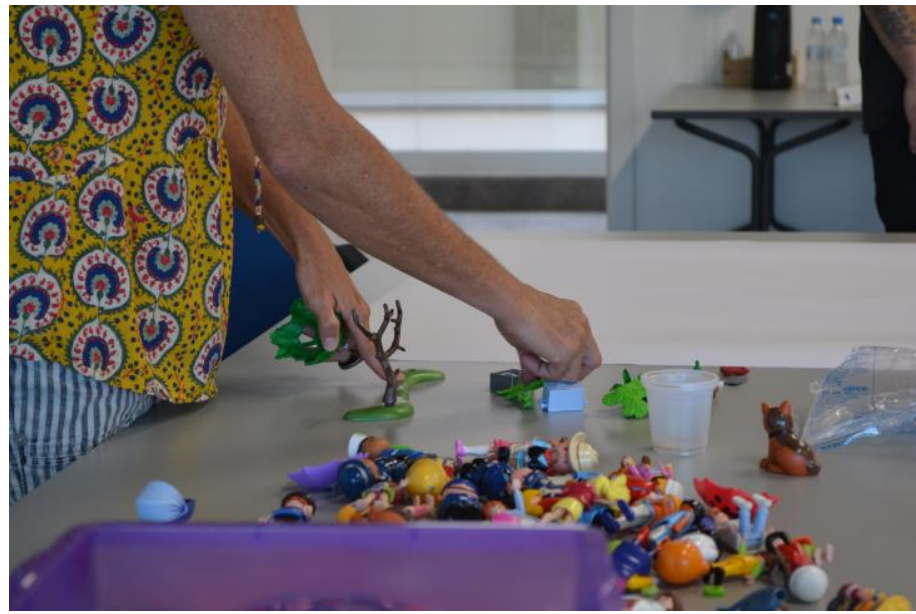

Fonte: Registrada pela autora.

O processo de projetação por cenários é construído a partir das trocas de relações, conceitos, ideias do grupo e de momentos individuais criativos. Em seguida, inicia um processo de maturação e aprofundamento das ideias e raciocínios projetados, que são captados por meio da Fotografia 4.

Fotografia 4 - Processo de projetação por cenários no WS: movimentos individuais criativos e maturação

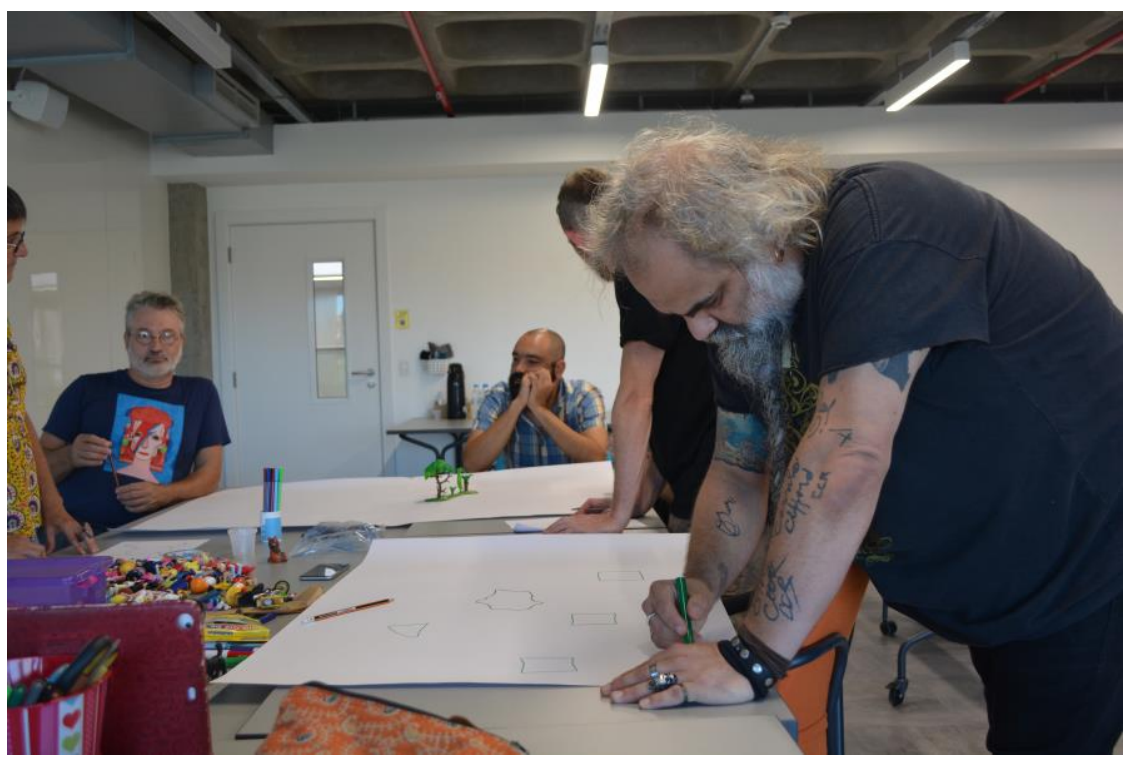

Fonte: Registrada pela autora.

\subsection{Projetando para Além de Pedaladas}

Apresenta-se, na sequência, a descrição dos projetos por cenários desenvolvidos e defendidos pelo grupo no desenvolvimento do WS. Bem como, a visualidade produzida ao longo do processo de criação. 
A Cidade Átomo é descrita por PWS5 da seguinte forma: "[...] basicamente, é a partir da ideia que PWS3 falou dos parques interligados que era uma ideia da outra cidade, mas que sejam elevados e nestas zonas - claro, não vai ser só parques, mas pode ter museus, lojas, este tipo de coisas que movimentam economicamente e, nessas vias que ligam os parques, só poderia, só seria para pedestres, ciclistas e transportes públicos pequenos, transportes coletivos pequenos, tipo um trenzinho elétrico, tipo bondinho, aquelas coisas que tem em Amsterdã, ou até um próprio aeromóvel".

Fotografia 5 - Visualidade produzida para a Cidade Átomo

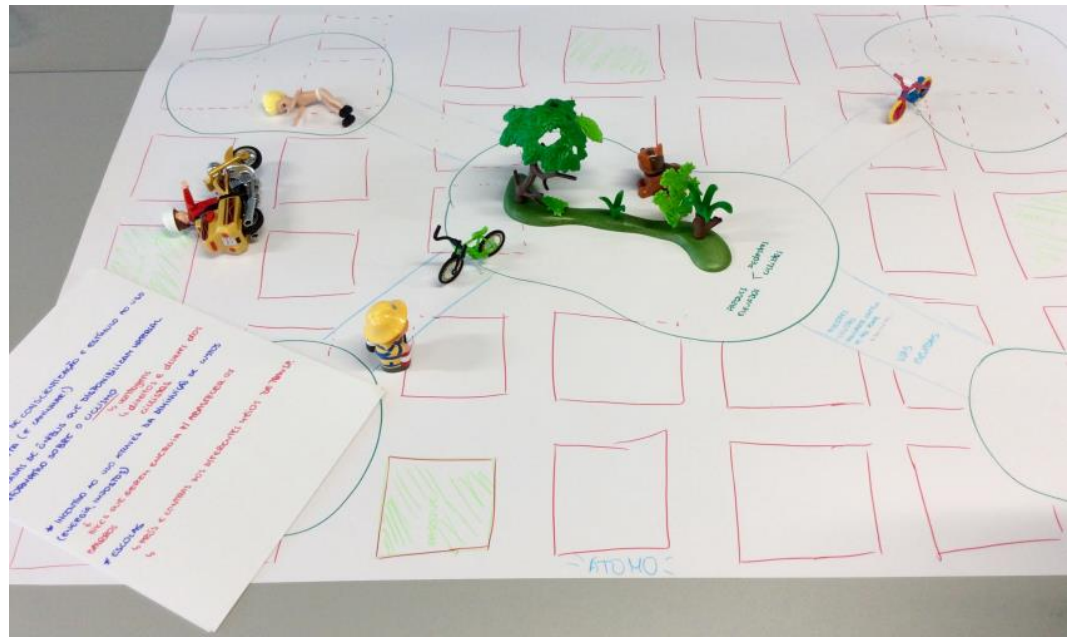

Fonte: Registrada pela autora.

Cicloruas é a denominação dada por PWS4 ao final da defesa da cidade. "Colocar a educação na rua, em outdoor, placas, locais que possam acessar as pessoas. Materiais que possam ser acessados pelas pessoas, por exemplo, no Parque da nossa cidade que vai ser interligado com todos os parques e praças e que vai ter as ruas, as vias para bicicletas e pedestres e ter um empréstimo, tipo as paradas de ônibus que tinha livros para as pessoas pegarem, ter disponível material sobre ciclismo, sobre bicicleta, vantagens, desvantagens e regras".

Fotografia 6- Visualidade produzida para a Cidade Cicloruas: trajetos e manifesto

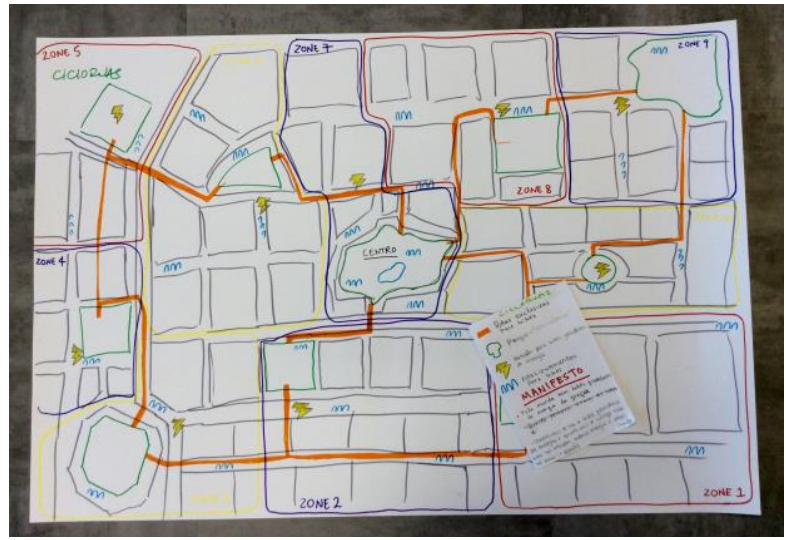

Fonte: Registrada pela autora. 


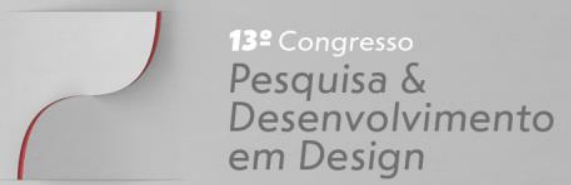

A Cidade Rodável apresentada por PWS2 tem como proposta uma cidade onde: "[...] a ideia de suprimir uma faixa das ruas para que ela fosse agregada ao espaço viário de pessoas e bicicletas, elas seriam em níveis distintos uma separação sem cercas. Uma parte mais alta atenderia as pessoas e as bicicletas e pequenas motos na faixa de baixo e os carros seriam numa faixa menor e mais baixa. Para compensar o estreitamento de carros, o transporte coletivo seriam ônibus grandes, que pudessem agregar, carregar bicicleta e coisa. Além disso, que fossem grandes no sentido de altura para diminuir número de ônibus nas ruas. Seria essa a Cidade Rodável".

Fotografia 7 - Visualidade produzida para a Cidade Rodável

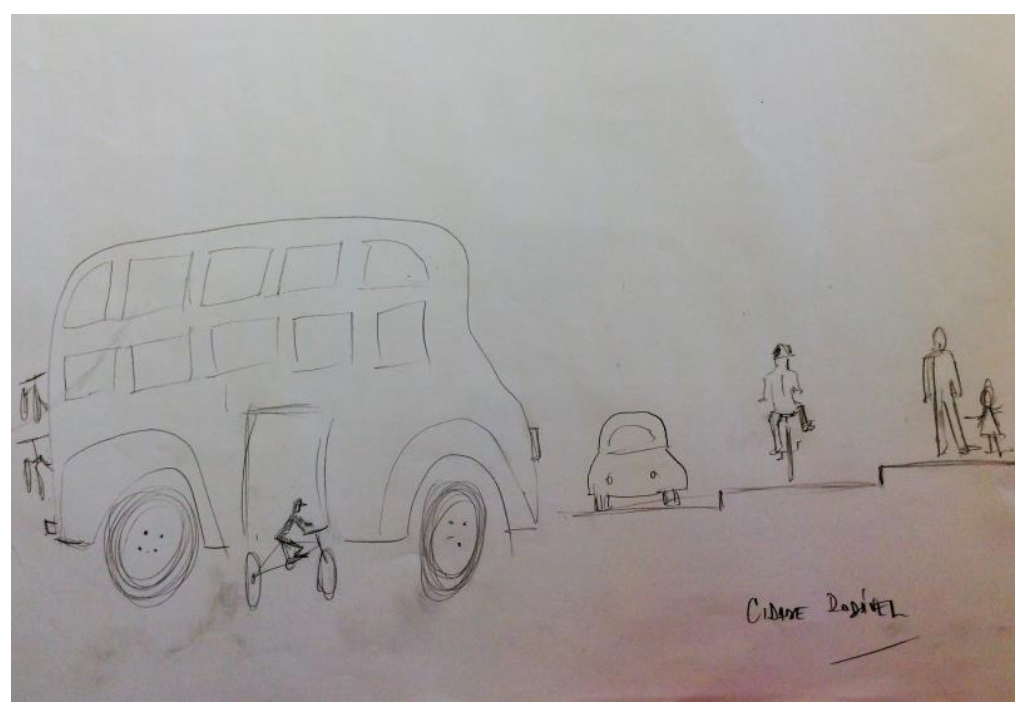

Fonte: Registrada pela autora.

A Cidade Asteroide envolveu o grupo com contribuições de PWS1, PWS2, PWS3 e PWS4 para a cidade projetada que falaram, simultaneamente, na defesa da cidade: "parques interligados por ruas pequenas, não fica algo muito ciclável. Como tu gira a cidade inteira, tenho que ir no banco, na imobiliária, uma cidade que se use sempre? Os oásis são parques ao invés de postos de gasolina, por exemplo. E entre cada um destes parques ter caminhos específicos para bikes onde o trânsito de carros não seja interrompido, mas onde as bicicletas possam andar com segurança no meio da rua. E as bolas são os parques? A terra poderia ser para baixo e a outra parte elevada. Ao redor destas áreas são ruas como a gente conhece com trânsito híbrido, normal. A gente colocaria os quiosques para ter acesso à água gelada, câmera da bike. Grandes avenidas de Buenos Aires, como se fosse avenidas grandes só para bicicletas e pessoas com lojas e grande, muito grande, assim embaixo, mais próximo do que a gente conhece". 


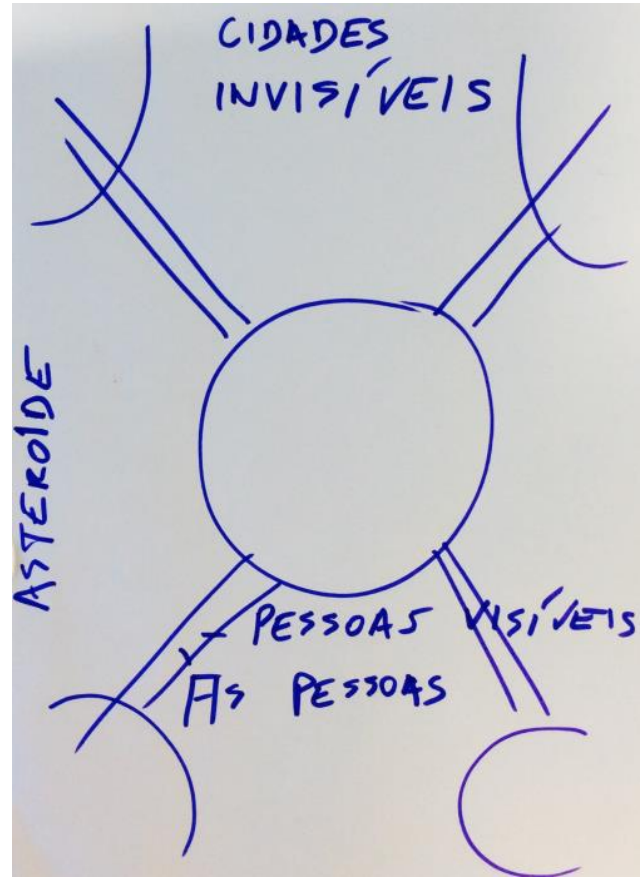

Fonte: Registrada pela autora.

\section{Considerações Finais}

Ao apresentar neste artigo um dos percursos da pesquisa Desafios para uma Cidade Ciclável: Um Exercício de Design Estratégico, foi possível aprofundar o olhar e acolher os processos que surgiram e que se desenvolveram no decorrer do caminho escolhido. Desta maneira, abriu-se um campo para que os processos pudessem se manifestar e potencializar o ato de metaprojetar com base no substrato oriundo do próprio processo, o que torna adequado realizar considerações de ordem complementar e reflexiva.

O estudo partiu de uma proposta de elaborar projetos através de cenários para um contexto frágil de mobilidade ciclável buscando compreender a dinâmica dos dispositivos sociotécnicos ciclovias, ciclofaixas e ciclorrotas, como sendo atores objetos fundamentais ou não na construção da Cidade Ciclável. Com base na metodologia aplicada atingiu-se o entendimento de que para a construção de uma Cidade Ciclável não se faz essencial a implantação de tais dispositivos. Eles auxiliam, no entanto, não são manifestados como indispensáveis para o deslocamento dos atores sujeitos. A conscientização das pessoas e a informação clara sobre a presença de ciclistas e pedestres no convívio com motoristas num mesmo espaço, essa sim é manifestada como pertinente.

Assim, cria-se a oportunidade para a construção de uma narrativa entre sujeito-corpo, sujeito-objeto e sujeito-sentido que leve à conscientização e, consequentemente, à educação ao fomentar um processo de transformação incremental. Uma narrativa que carregue a relação do sujeito-corpo que transita pela rua, numa relação do homem com a cidade. Um sujeito-corpo que 
pode se mover independente do meio e das imperfeições nele contidas.

No workshop, atores sujeitos mais técnicos como: agentes públicos, empresários e agentes atuantes na sociedade podem fazer parte de estudo futuro mais verticalizado com o propósito de investigar como se dá o processo de projeção de cenários de quem pensa de forma técnica e sistematizada a mobilidade nas cidades. Todo esse corpus proporcionou o exercício da prática metaprojetual. Os atores sujeitos apresentados vivem os espaços de uma cidade que, independentemente dos atores objetos, percorrem-na de diferentes modos: pelo ato de caminhar, pelo ato de pedalar e pelo ato de utilizar o transporte coletivo ou privado, em sintonia ou de forma sequencial, que é o que aparece de forma clara nos cenários projetados. Não se descarta, em nenhum momento os atores objetos, convive-se com eles e colocam-se em cena soluções possíveis de harmonizá-los no dia a dia das cidades. Logo, concentrar a atenção no processo permite o fluir de uma ideia implícita de lançar mão da semente da inovação já na essência ao levar em consideração a lógica do pensamento complexo, no qual o ato de criar e inovar estão ligados.

Outro aspecto observado no estudo é que ele reafirma a ideia de ampliação do conceito de design estratégico, no processo e encaminhamento aparentemente final, ao colaborar tanto para a interpretação da realidade quanto para a própria transformação dela. Ao compreender design como uma área abdutiva, que através dos exercícios imaginativos transita pelo tangível e intangível, a vivência nas cidades evolui e involui a todo instante. Os processos de projeto de uma Cidade Ciclável pelo caminho da inovação social mostram-se relevantes, quando são aproximados dos processos de significação para que haja a compreensão e a formulação de sentido da narrativa urbana. São os processos criativos responsáveis por transformar as cidades e fazer transitar os atores sujeitos e atores objetos entre o possível e o real.

Por fim, o artigo dedicou atenção para contribuir no desenvolvimento da construção de um conceito de Cidade Ciclável à luz do design estratégico. Como vem a ser a Cidade Ciclável que viva para além da infraestrutura, quando essa estrutura de fato não existe ou se apresente como um contexto frágil para o deslocamento por bicicleta. É a consciência coletiva e a educação que aparecem como pano de fundo nos cenários projetados para cidades que têm que lidar com imperfeições, onde dispositivos não funcionam, efetivamente, e onde o modo de agir e pensar fica colocado em segundo plano. Nos cenários projetados no WS e nas narrativas expressadas, constatou-se uma riqueza contida na processualidade e na ação de metaprojetar que estimulam um conjunto de visualidades e cenários imaginativos. Esses nutrem a prática e dão lastro ao conhecimento metaprojetual e de projeto por cenários, bem como incentivam a crítica reflexiva constante por meio de estudos aprofundados.

\section{Referências}

BENTZ, I.; FRANZATO, C. O princípio do deslocamento: níveis e processos. Working Paper, 2016.

BENTZ, lone. A arte nos espaços urbanos: narrativas visuais. Strategic Design Research Journal, [S.I.], v. 7, n. 1, p. 7-14, Jan./Apr. 2014. Documento em PDF.

BENTZ, lone. Do ponto de vista à produção de sentidos: um percurso metodológico. In: REYES, Paulo. Projeto por cenários: o território em foco. Porto Alegre: Sulina, 2015. p. 224-244.

CANEVACCI, Massimo. A cidade polifônica: ensaio sobre a antropologia da comunicação urbana. São Paulo: Studio Nobel, 1997. 
CANEVACCI, Massimo. Culturas extremas: mutações juvenis nos corpos das metrópoles. Rio de Janeiro: D\&A, 2005.

CHARAUDEAU, P. Discurso das mídias. São Paulo: Conexão, 2009.

DE MORAES, D. Metaprojeto como modelo projetual. In: DE MORAES, D.; DIAS, R. A.; BOM CONSELHO, R. (Org.). Método. Belo Horizonte: Santa Clara. 2011. p. 35-51. (Cadernos de estudos avançados em design). Disponível em: <http://www.tcdesign. uemg.br/pdf/Metodo_completo.pdf>. Acesso em: 15 nov. 2016.

DUARTE, R. Entrevistas em pesquisa qualitativas. Educar, Curitiba, n. 24, p. 231-225, 2004. Documento em PDF.

FONTANILLE, Jaques. Significação e visualidade: exercícios práticos. Porto Alegre: Sulina, 2005. FRANZATO, C. et.al. Inovação cultural e social: design estratégico e sistemas criativos. In: FREIRE, K. (Org.). Design estratégico para a inovação cultural e social. São Paulo: Kazuá, 2015. p. 157-182. FURTADO, Beatriz. Imagens eletrônicas e paisagem urbana - intervenções espaço-temporais no mundo da vida cotidiana: comunicação e cidade. Rio de Janeiro: Relume Dumará, 2002.

GIACCARDI, E. Metadesign as an emergent design culture. Leonardo, [S.I.], v. 38, n. 4, p.324-349, 2005. Disponível em:_http://transtechresearch.net/wpcontent/uploads/2012/03/giaccardielisa.pdf>. Acesso em: 25 jun. 2016.

JACOBS, Jane. Morte e vida de grandes cidades. 3. ed.São Paulo: WMF Martins Fontes, 2011. MANZINI, E.; JÉGOU, F. Design degli scenari. In: BERTOLA, P.; MANZINI, E. Design multiverso notas de fenomenologia do design. Milano: Edizioni POLI design, 2006. p. 189-207.

MANZINI, Ezio. Design para a inovação social e sustentabilidade: comunidades criativas, organizações colaborativas e novas redes projetuais. Rio de Janeiro: E-papers, 2008.

MANZINI, Ezio. Making things happen: social innovation and design. Design Issues, [S.I.], v. 30 n. 1, 2014. Documento em PDF.

MERONI, A. Strategic design: where are we now? reflection around the foundations of a recent discipline. Strategic Design Research Journal, [S.I.], v. 1, n. 1, July/Dec. 2008. Documento em PDF. MORIN, E. Introdução ao pensamento complexo. Porto Alegre: Sulina, 2011.

NETTO, Vinicius M. A urbanidade como devir do urbano. Revista EURE, [S.I.], v. 39, n. 118, p. 233263, 2013. Documento em PDF.

ORLANDI, E. (Org.). Cidade atravessada. São Paulo: Pontes, 2001.

PORTO ALEGRE. Prefeitura Municipal. EPTC completa 41 km de ciclovias com redução de acidentes fatais. Porto Alegre, 9 maio 2016b. Disponível em:

$<$ http://www2.portoalegre.rs.gov.br/eptc/default.php?p_noticia=186367\&EPTC+COMPLETA+41+KM+D E+CICLOVIAS+COM+REDUCAO+DE+ACIDENTES+FATAIS>. Acesso em: 20 maio 2016.

REYES, Paulo. Projetos por cenários: o território em foco. Porto Alegre: Sulina, 2015. 